\title{
Speechless: Rolling in the right direction
}

\author{
Matthew MacCarthy \\ University of Pittsburgh/UPMC Children's Hospital of Pittsburgh, 21 Charley Horse Road, Columbia, SC 29223, \\ USA \\ Tel.: +1 720 6283021; E-mail: drdeeptone@gmail.com
}

Keywords: Cerebral palsy, disability representation, adolescents

\section{Nothing about us, without us.}

Originating in $16^{\text {th }}$ century Central European politics [1] and subsequently becoming a slogan for democratic norms, the phrase in its English form came into use in disability activism in the 1990s and has since come to represent many marginalized groups. In the disability community, it is a rallying cry, a call for awareness of the decades-old trend of casting temporarily able-bodied actors and actresses in roles with disabilities. Often, especially recently, these decisions are made ostensibly with narrative purpose: many actors living with disabilities cannot portray both the before and after of an acquired or degenerative condition. Glee's Artie Abrams, a glee club member with a spinal cord injury, couldn't have a dream sequence about rising from his chair and busting a move [2] if portraying actor Kevin McHale wasn't a prodigious dancer. But the former situation could be remedied by alternative narrative choices or double casting, while the latter would benefit from an improved recognition of the profound beauty and athleticism of wheelchair dance. Then, there are a host of less well-intentioned casting decisions, stemming from an ignorance of the depth of the disabled community's talent pool or even from an outright refusal to search within it. It seems that stories about characters living with disabilities are deemed worthy of telling, but often through a lens of convenience or star power that both reinforces ableism through magnetism for award nods, and misrepresents the critical lived experience of the characters.

In 2016, into this controversial landscape rolled ABC's Speechless, a family sitcom centered on the
DiMeos, a plucky family of five whose oldest teen, JJ, has Cerebral Palsy (CP) and utilizes a power wheelchair. The titular impairment requires JJ to use a communication board as well. The show instantly sets itself apart in that Micah Fowler, who portrays JJ, has CP, and the show's creator, Scott Silveri, based the show and JJ's character on his own family and brother, Gregory, who had CP and was nonverbal. The lived experiences of creator and star make their indelible, genuine mark on every aspect of the show, and rather than treat those experiences as secondary, the narrative lovingly embraces them. JJ has dream sequences too, even ones involving superpowers, and he's still in his chair and unable to speak in those dreams. Like it does for many of us, disability forms a part of his identity.

Speechless comes out of the gate swinging against stereotypes, ableism, and accessibility, and never even slows down until several episodes in. The very first formal introduction of JJ's character has his fiercely (over)protective mother, Maya, yelling from their wheelchair van lift at a bystander, "[His arms] need a bit of a tune up, but he's all there up here, and he has a thing about staring!" The pilot episode alone hits on accessible parking (or lack thereof), building accessibility, school and district resources, the common issue of relocation to find better services for a child living with disabilities, disproportionate attention on these children relative to their siblings, conflating forms of discrimination, lumping all disability together ("My cousin is deaf, so he gets it"), and my personal favorite: the human impulse now wryly referred to as 'inspiration porn'. JJ wheels into his classroom for the first time to a standing ovation, shouts of "You're an inspiration!" and calls for 
him to run for class president. I cringed, wondering if this show was going to jump away from disability as a vehicle for pity only to land on disability as a vehicle for unwarranted laud. Thankfully, JJ quickly admonishes his classmates for this behavior. In fact, the narrative returns again and again to $\mathrm{JJ}$ wanting equity in the form of a lack of handouts, while his mother is often the one who catches herself arguing for them.

Almost every time I became worried that the show was edging toward stereotype, it would either reverse course or immediately lampoon itself. Maya is the quintessential overprotective, tooth-and-nail fighter who refers to herself as a "special needs mum," but she cools and eases with the show's progression. Early on, Maya responds to a difficult task with "We have challenges other families don't," only to be derided by JJ's younger siblings, Ray and Dylan, for overusing and abusing that excuse. When JJ's aide, Kenneth, takes him for a day out and the pair discover the ability to cut to the front of virtually any line, it's Kenneth who grows to abuse the privilege, angering $\mathrm{JJ}$ for "taking [his] voice" in deciding where to go. When JJ joins a dating app, his first dates are with a girl who only dates wheelchair users, a girl looking for a good college admissions essay, and a girl wanting to 'heal' him - all of whom are promptly rejected. An entire episode deals with 'shipping,' a slang term referring to bystanders' desire for two people to be romantically involved, and how that is commonly applied to matching two people with disabilities (or, in Kenneth's parallel case, two people of the same racial background).

There's a lot to love here as a person living with $\mathrm{CP}$ and as a physiatrist. My very first moment of curiosity was about JJ's communication board, which is a static collection of words and letters that he uses via an over-the-ear laser pointer, with someone else reading aloud for him. I kept wondering whether it was a lack of resources, financial or otherwise, that kept the family away from a speech generating device. JJ explains subsequently that he tried one of these devices but prefers the human touch of having his thoughts read aloud. Not only does this lend itself hilariously to various mid-sentence reactions from his readers (not to mention Micah Fowler having just about the most expressive face I've ever seen on screen), it also allows JJ's voice to change based on setting and context, utilizing the voices of his siblings, parents, aide, friends, and teachers to masterfully varying effect. The second Christmas episode involves a home video JJ gives to his family, initially displaying his communication board slowly spelling out "This-is-how-I-sound-to-you," be- fore a narrator says perfectly fluently "But this is how I sound to me," which, even as someone with experience with oral motor dysfunction, invited me to reflect on how we can better work to give people their own voices. The show deals explicitly with dignity and whether safety, basic needs or quality of life are the more important drivers thereof. I also love the dynamic between JJ and Kenneth, which started on the exact right foot with $\mathrm{JJ}$ asking if the aide had any questions, only to divert his partially-formed inquiry about social perspectives onto things like "Do I handle bathroom stuff?" and "Does your dude stuff work?" The show is real. It may get a bit preachy at times, but it does not shy away from the difficult aspects of living with, or having a brother/son living with, a disability. The Cerebral Palsy Foundation (https://www.yourcpf.org/), for which Fowler is an ambassador, worked directly in collaboration with the show makers, releasing informative content for families on their website focusing on a theme from each week's episode (available at https://www.yourcpf.org/speechless/). Zach Anner, YouTube comedy legend and disability advocate, lends his voice and humor to the show as JJ's recurring mentor and mischievous friend. And while much of the focus is on $\mathrm{JJ}$ and his journey, every one of the other major characters gets his or her time to air struggles and challenges as well as time in the spotlight, both alone and in the context of individual contributions to the family dynamic.

Ultimately, Speechless does a fantastic job of crafting a hilarious, heartwarming narrative around a family and teen dealing with disability, and addressing a staggering array of disability issues, all while remaining true to itself. Some of it is over the top. The humor fizzles at times as the seasons go on, and some gags rely on regression of character development to work. But the core of the narrative is each member of the family (not just JJ) finding their voice, and the focus here is entirely human - not disability, not advocacy, and not accessibility. In his IMDB bio [3], Micah Fowler mentions that he "hopes viewers will get to know JJ as a very typical person, to the point that they don't even see JJ's disability, but see his personality, potential and the person he is." Three seasons of Speechless accomplish this goal with grace, self-awareness, and heart. I'll come back to the show again for its comedy, but there are plenty of lessons here, too. Disability representation is improving, as is society's awareness and acceptance. With that comes broader accessibility and the chance for the healthcare system to fall increasingly into the background in fighting for equity in these people's lives. 
The DiMeos are shown being frequently told by doctors, teachers, and friends to "be realistic" about goals regarding JJ's life, access, and achievements. There will always be fine lines between optimism and false hope, but as a physician, I would encourage readers, whatever your connection to the disability community, to follow the show's closing advice and "be unrealistic."

Speechless is streaming on Hulu and available for purchase on Amazon Prime Video, the Google Play and iTunes stores, and YouTube.

\section{Conflict of interest}

The author has no conflicts of interest to report.

\section{References}

[1] Van Erdeghem R. Nothing About Us Without Us: Impressions of the Skábmagovat Film Festival. Current developments in arctic law. 2019; 7: 56-65.

[2] Dream On [television broadcast] Glee Fox Broadcasting Company. 18 May 2010.

[3] Internet Movie Database. Micah Fowler: Biography [Internet]. [Cited 2020 Dec 23] Available from https://www.imdb.com/ name/nm5094896/bio?ref_=nm_ov_bio_sm. 